\title{
Transparent Digital Contents Sharing for Science Teachers
}

\author{
Thongchai Kaewkiriya ${ }^{1}$, Ryosuke Saga ${ }^{2}$, and Hiroshi Tsuji ${ }^{2}$ \\ ${ }^{1}$ Faculty of Information Technology, Thai-Nichi Institute of Technology, \\ 1771/1, Pattanakarn Rd., Suanluang, Bangkok, Thailand \\ thongchi@tni.ac.th \\ ${ }^{2}$ Graduate School of Engineering, Osaka Prefecture University, \\ 1-1, Gakuencho, Naka-ku, Sakai, 599-8531 Osaka, Japan \\ \{sagal, tsuji@\}cs.osakafu-u.ac.jp/
}

\begin{abstract}
To support science teachers for preparing their classes, this paper presents concepts and principles on digital contents sharing. The proposed framework is divided into three parts: The first part proposes the maturity levels for science teacher activities based on SECI model and CMMI. The second part designs the system components on DLMS (Distributed e-learning management system) which allows science teachers to share digital contents efficiently. The third part illustrates the scenario how the proposed framework works. The possibility for prototype system based on REST (Representational State Transferred) ful Web service is also discussed. This proposal expects to save time for preparing digital contents for science teachers as they mature on digital contents.
\end{abstract}

Keywords: e-Learning, Digital content sharing, Knowledge-Network, Maturity Model, Knowledge Management.

\section{Introduction}

In recent years, the information technology in the education field becomes important especially for the distance learning through the Internet [1]. Such e-learning system basically consists of three components: learning management system [2] (LMS); learning contents; and infrastructure technology which is found as a common part of e-learning system. The volume of digital contents on the Internet has increased day by day for teachers as well as for students. The varieties of digital contents are scattered over schools. Normally each school has provided an LMS for teachers, students, and an administrator. Then one of the problems for teachers is to consume time for creating and sharing digital contents even if there have been already excellent contents in other school. Thus the teacher should create and share digital contents only in his school's LMS. Then, how can a teacher share digital contents with other schools' teachers for preparing classes efficiently.

Our answer is to provide transparent digital contents sharing mechanisms. Let us review the current status on information sharing method. There are still teachers who 
hesitate to use information technology. They can exchange tacit idea on teaching materials only based on discussion. Using standalone PC (Personal Computer), some teachers create digital contents as teaching materials which is externalized from his brain. To share them as explicit knowledge, they should copy them into media such as USB memories. Then there is less chance to collect large number of digital contents effectively. If there is an LMS in school which is connected with LAN, each teacher has chance to reuse digital contents which are externalized and to disclose his idea to others. Our discussion occurs at the next stage: each school has its LMS but there is no way to exchange digital contents over schools.

The previous research, digital content sharing could be done in a social network service with maturity level for science teacher [3]. In addition, the design of knowledge-network for Japanese science teachers has been presented [4] to support knowledge sharing among science teachers: 1) relationship 2) reputation 3) personalization. Research in [3] and [4] focused on three factors. However, how to implement the proposal was strongly dependent on social network service. Then it was difficult to describe scenario how teachers mature on digital contents.

Referring concepts of SECI model [5] and CMMI model [6] [7] for considering pioneers followers, this research introduce maturity model for them. Next, this paper will describe what DLMS is and how it works for future digital contents sharing in the future. For prototype, we will use a RESTful web service [8] [9] in order to develop. Then this paper will present scenario how teacher mature and what DLMS should do.

\section{Digital Content for Science Teacher}

\subsection{Pioneer and Follower}

To help science teachers, Japanese government has prepared digital contents. Today there are more than 45,000 users and more than 40,000 contents. The examples of digital contents are shown in Fig. 1. The contents are stored in central database and there is keyword query as well as index.

However, there are some problems as follows:

1. While there are pioneers, there are also followers. In fact, some teachers are so active that they are positive to prepare class with digital contents by themselves. They may modify the prepared digital contents for his class because sometimes contents may be too long and too redundant. Then his modification cannot be shared. On the other hand, other teachers may be novice for IT and hesitate to be a leader on digital contents.

2. IT environment of school is different from each other. Some schools may be equipped with up-to-date technology and others may not. On the other hand, it is also true that such environment will be upgraded year by year once the digital contents work well for classes. Then it is still common: when the environment is upgrades, there should be extra tasks such as database moving and usability change. 

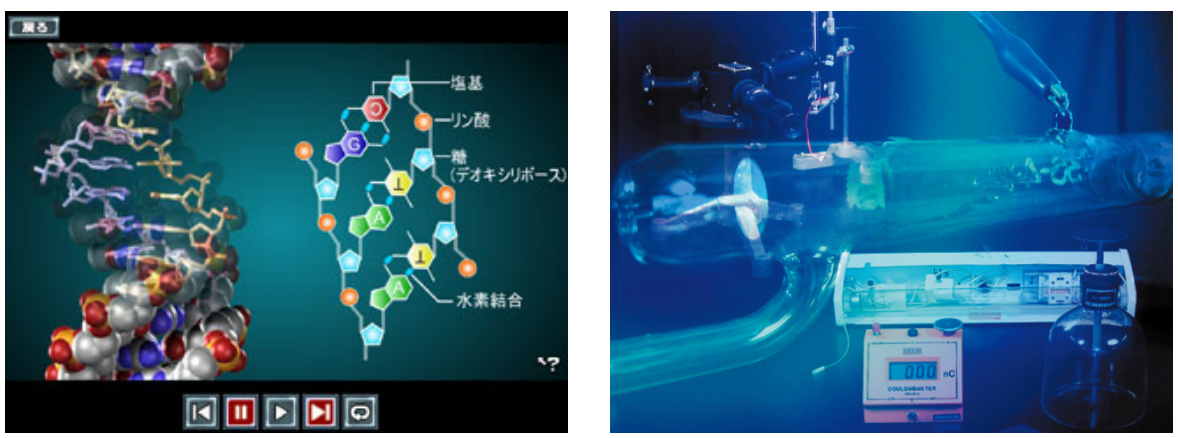

Fig. 1. Example of digital contents sharing

Next, let us consider the initial state and ideal state. At the initial state, there is no IT in a school. Both pioneer teacher and follower teacher has no chance to use digital contents but exchange idea how to start using them at first. At the ideal state, the pioneer teachers will make plan for using digital contents and give lesson at class. They will review the class and may modify both his talk and digital contents. He will be active to open his idea for others. Learning good practice from pioneer teachers, the follower teachers start using digital contents. Even if he hesitates to express his idea, he likes to search digital contents which fit to his class.

Then what we should consider is scenario how we give chance science teachers for transit from the initial state to the ideal state.

\subsection{Maturity Upgrade Process}

To develop teachers' maturity level higher, let us consider the bias for establishing model for digital contents sharing. This research introduces two biases: CMMI (Capability Maturity Model Integration) [6] [7] and SEKI model.

CMMI is well-known in software development process. CMMI supposes that upgrading maturity level is measured by the existence of process which implies the level of capability. The original CMM includes five maturity levels: initial, repeatable, defined, managed and optimizing.

SEKI model is prepared for knowledge creative company [5]. It includes four spiral processes: knowledge socialization (S), knowledge externalization (E), knowledge combination (C), and knowledge internalization (I). In our context, $\boldsymbol{S}$ can occur even if there is no special tool and $\boldsymbol{I}$ can occur if there is search mechanism. To implement $\boldsymbol{E}$, there should be at least personal storage and preferable shared storage. For $\boldsymbol{C}$, there should be computer network for sharing knowledge.

Let us consider the relation between CMMI model and SECI model. At initial stage, all teachers have old-fashioned class and there is no process in school for using digital contents. Then without IT there should be communication in school as socialization. Communication contributes to encourage teacher to improve his class. 
Table 1. Table of maturity for science teacher

\begin{tabular}{|c|c|c|c|c|c|c|c|c|c|}
\hline Level & Detail & \multicolumn{7}{|c|}{ Teacher (User) } \\
\cline { 3 - 10 } & & Tool & $\begin{array}{c}\text { Rika } \\
\text { Network }\end{array}$ & $\begin{array}{c}\text { Own } \\
\text { school } \\
\text { DB }\end{array}$ & $\begin{array}{c}\text { Other } \\
\text { school } \\
\text { DB }\end{array}$ & S & E & C & I \\
\hline 1 & No IT & - & - & - & - & $\bigcirc$ & $\mathbf{X}$ & $\mathbf{X}$ & $\mathbf{X}$ \\
\hline 2 & Stand alone & PC & $\bigcirc$ & - & - & $\bigcirc$ & $\mathbf{X}$ & $\mathbf{X}$ & $\bigcirc$ \\
\hline 3 & $\begin{array}{c}\text { School } \\
\text { Network }\end{array}$ & LMS & $\bigcirc$ & $\bigcirc$ & - & $\bigcirc$ & $\triangle$ & $\triangle$ & $\bigcirc$ \\
\hline 4 & $\begin{array}{c}\text { Global } \\
\text { Network }\end{array}$ & DLMS+SNS & $\bigcirc$ & $\bigcirc$ & $\bigcirc$ & $\bigcirc$ & $\bigcirc$ & $\bigcirc$ & $\bigcirc$ \\
\hline
\end{tabular}

At final and ideal state, teachers are so active to share good practice on digital contents. They not only use the prepared digital contents but also modify them and disclose their modification. They search the appropriate contents not only from his school but also from other schools. It means that sophisticated digital contents as good practice are transparently accessed by any teacher.

Overview of maturity upgrade process is summarized in Table 1. Let us discuss each level carefully.

\section{Maturity 1}

This level is the traditional state before IT is available in school even if a teacher has IT skill. The teachers in this level share knowledge or experience among colleagues. But it is time consuming. Even if one finds good practice, it is not easy to share it with others in another school. There is no space to store it for others. The maturity level process is shown in Fig 2.

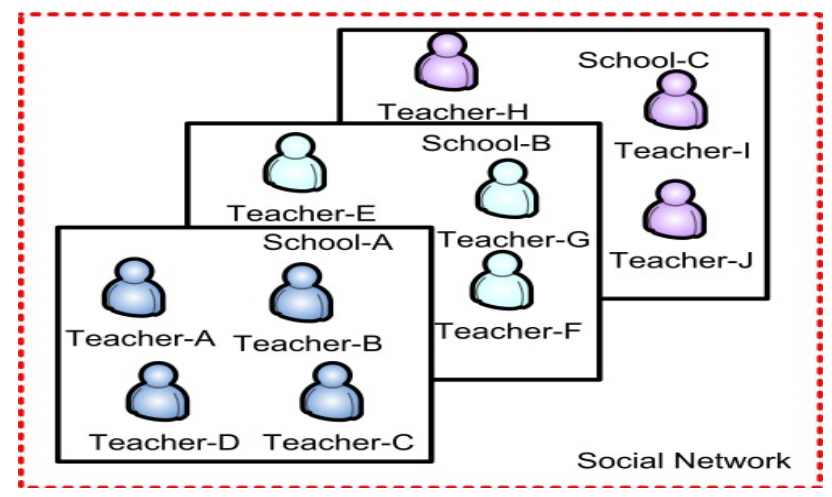

Fig. 2. The maturity level 1 process

\section{Maturity 2}

This level is the case that Rika-net appeared. If a pioneer teacher has standalone PC, he has chance to search digital contents stored in central DB. Viewing digital contents, he learns good practice, uses it in his class and stores his experience as his tacit 
knowledge. He may modify the digital contents for his class. Then even if the modified contents are available by other teachers, there is no chance to share it electronically. What he can do is to communicate with follower teachers on his practice in the meeting. Such socialization allows the follower teacher to start using digital contents. The process of maturity level 2 is illustrated in Fig. 3.

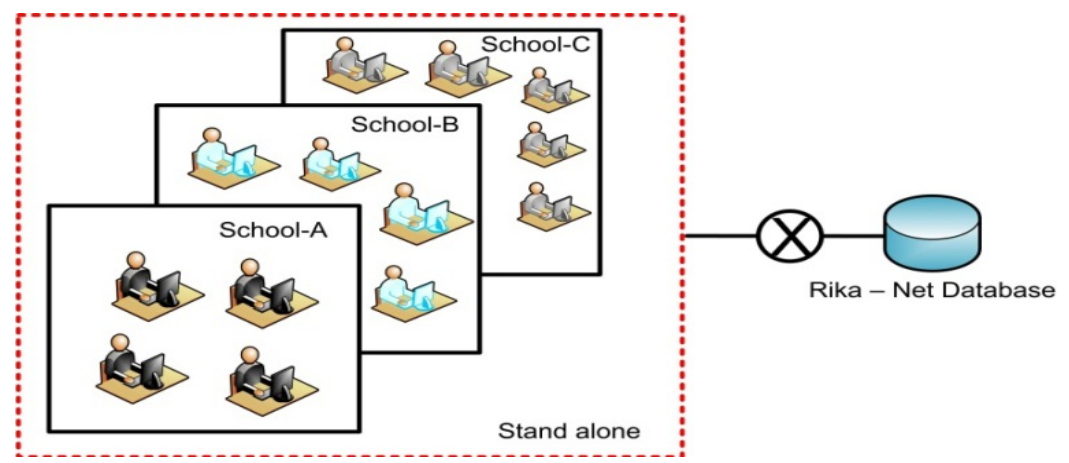

Fig. 3. The maturity level 2 process

\section{Maturity 3}

This level is a state where local network is available in a school. Teachers in this level use LMS in his school which allows them to share information electronically. Once one teacher finds good practice in Rika-net, he lets his colleagues know via LMS. Not only sharing knowledge or experience among teachers, pioneer teacher creates own digital contents, save and store in school's DB. Then the followers start using digital contents for their classes. While each school continues to store good practice in its LMS. there is no chance to share them over school unless they use special channel. The process of maturity level 3 is shown in Fig. 4.

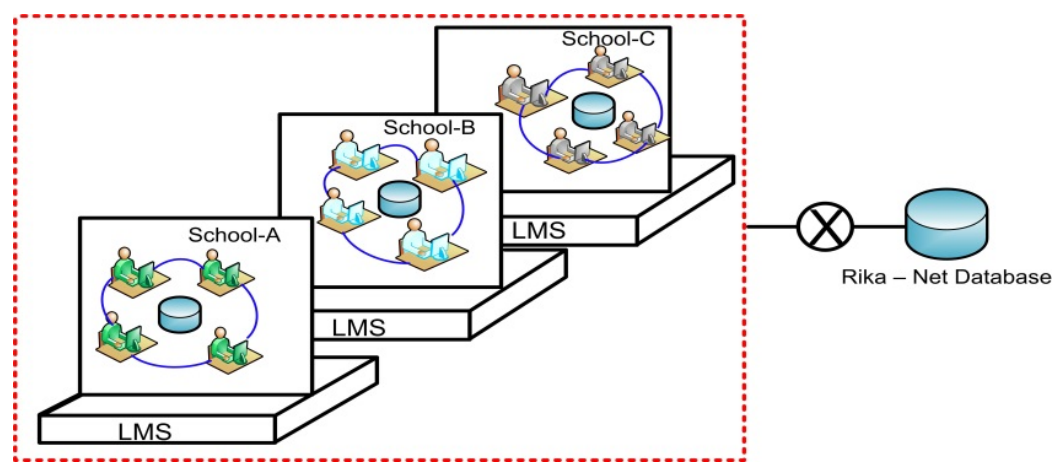

Fig. 4. The maturity level 3 process

\section{Maturity 4}

This level is the highest state on digital contents sharing for science teachers. There is DLMS which allows to access database in other school transparently. Once a pioneer 
teacher stores his good practice in his school LMS, everybody (not only teachers in his school but also teachers in other schools) has chance to access it without difficulty. They feel as if all contents were in one database. This transparency should owe to DLMS. The process of maturity level 4 is shown in Fig. 5.

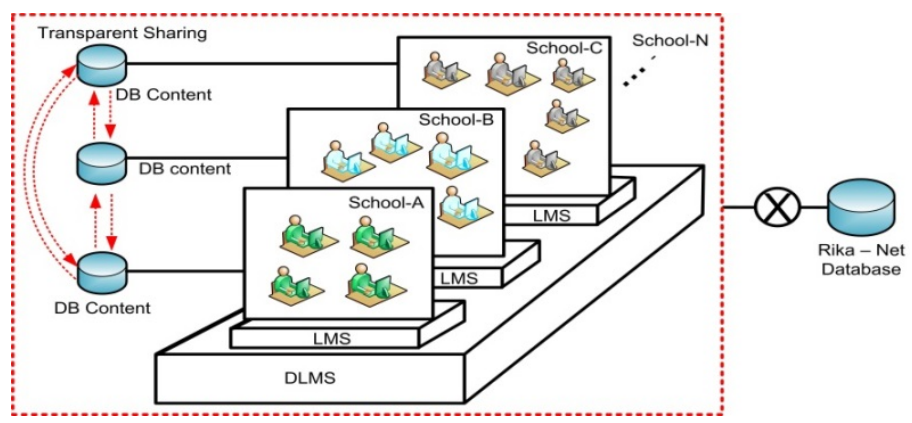

Fig. 5. The maturity level 4 process

\section{Distributed LMS}

\subsection{System Component}

Let us describe system components of distributed LMS which allows us to have maturity level 4 process. As shown in Fig. 6, there are more than two LMSs. Each school prepares LMS for science teachers in order to share knowledge based on digital contents. LMS composes of student's module as for student, admin module as for administrator, and section of teacher module. This research focuses on teacher module.

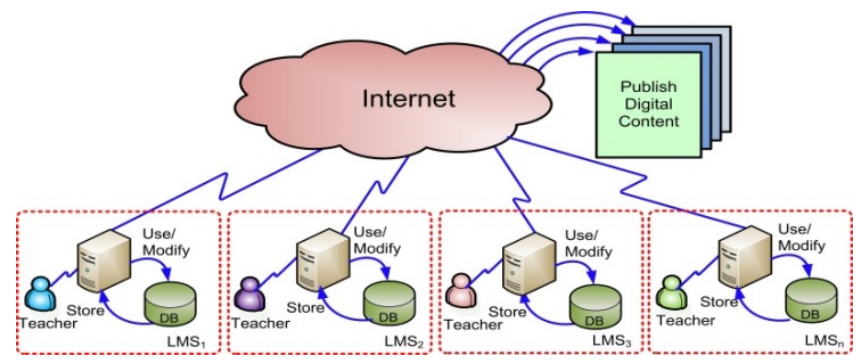

Fig. 6. The system component of DLMS

Then a teacher who is in $\mathrm{LMS}_{1}$ uses digital contents not only in his LMS of his school but also those in other schools. Under this environment any teacher has chance to externalize his tacit knowledge for other teachers. Once the digital contents are prepared, it can be accessed from any LMS. Thus prepared digital contents are combined as explicit knowledge. Finally, any teacher can search digital contents for his 
class over schools. If he learns something from new digital contents, it is regarded as internalization.

\subsection{Data flow of DLMS}

Let us next describe the data flow of DLMS by Fig. 7. Teacher who logins LMS will be able to study new digital contents which other teachers in the system have created. Note that the ability to create digital contents is based on the maturity level of the individual teacher.

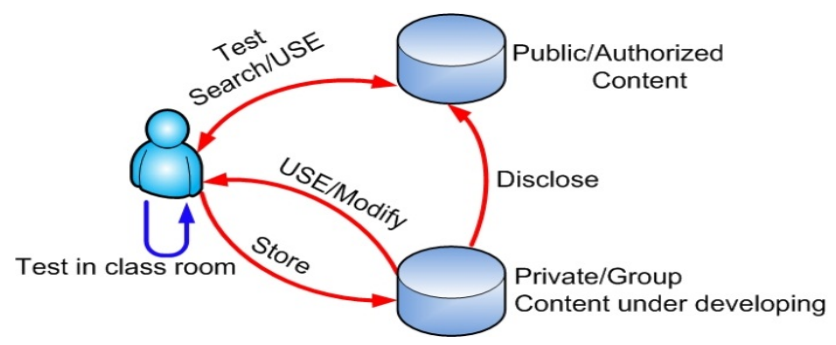

Fig. 7. The data flow of DLMS

Data flow indicates that a teacher is able to search digital contents from database of LMS. In addition, teacher can create digital contents, modify them into a private database of LMS. Also, he can disclose digital contents in private into published digital contents if their maturity level is four (Table 1).

\section{Scenario}

\subsection{Scenario-1}

Suppose that teacher-A should prepare class for earth project although he is not a specialist on this topic. Then he will ask his colleagues in his school by face-to-face communication if IT environment is not well organized. Only in the case that there is an expert, he can get solution as shown in Fig. 8.

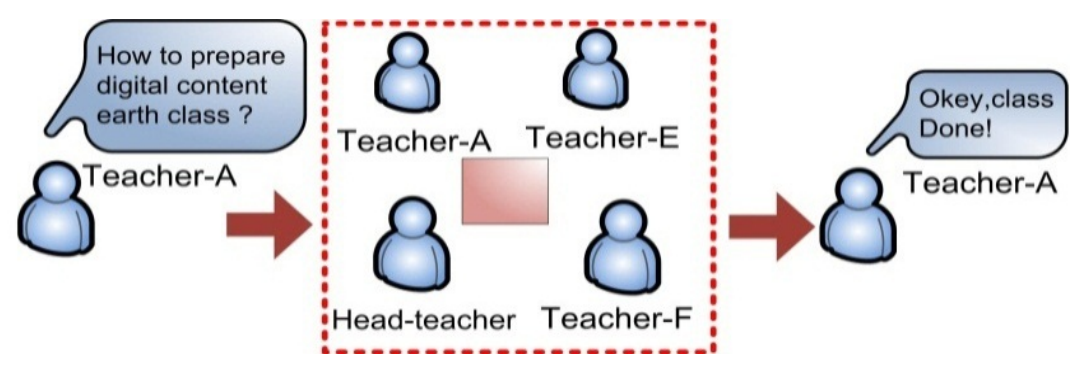

Fig. 8. Scenario-1 


\subsection{Scenario-2}

Assume that teacher-B has PC which is connected to Internet. Then he can search digital contents from DB content (Rika-net) network where there are lots of digital content on planet. He has chance to download digital contents and prepare classroom for his students. When he teaches digital content to students for a while, he may find that digital contents do not suitable to his class. Then he may go to consult with teacher-F and teacher-G who are experts in planet subject and have been doing research about planet subject. After discussion he can modify digital contents to prepare his classroom for the future. Scenario 2 is shown in Fig. 9.

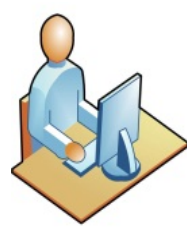

Teacher-B

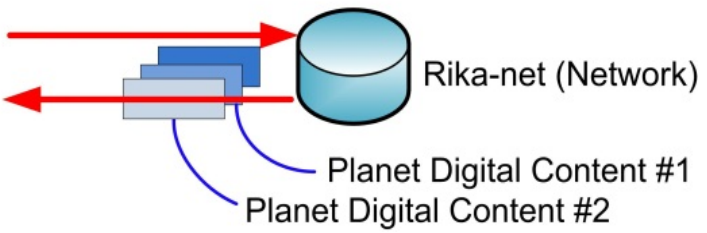

Fig. 9. Scenario-2

\subsection{Scenario-3}

Suppose that teacher-C would like to use digital contents on plant. He can search for digital contents from DB content (Rika-net) network but is aware that searched digital contents on plant are not enough. Downloading the prepared digital contents, he can modify them and saves them in his local storage for his colleagues. But there is still limitation because teachers in another school have no chance to use his good practice. Scenario 3 is shown in Fig 10.

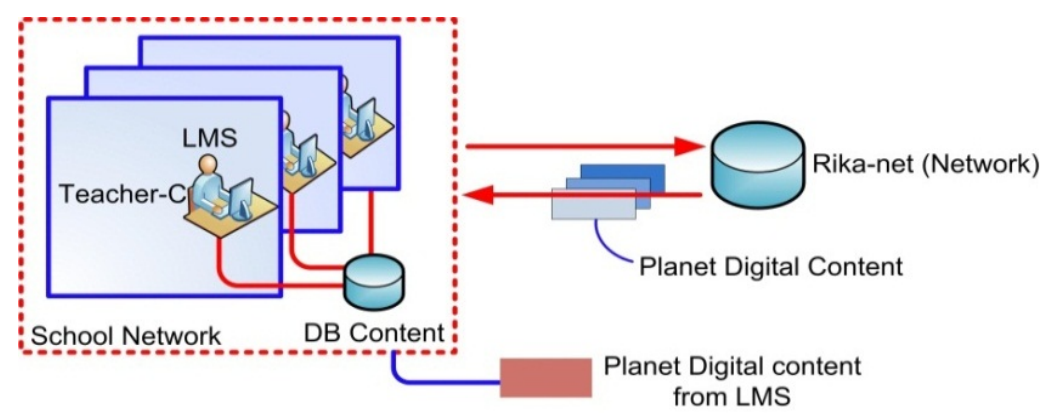

Fig. 10. Scenario-3

\subsection{Scenario-4}

Assume that teacher-D, J and $\mathrm{K}$ would like to use digital contents on Physics, Math and Chemistry respectively. They can search for digital contents from DB content 
(Rika-net) but they may fail. To prepare original digital contents for classes, they use DLMS for searching digital contents via Global network to confirm if right contents exist in other schools. If exists, they can down load as if it were in central database. When they download, they modify and save digital contents their local storage. They also use to distribute to those interested to download. Scenario 4 is shown in Fig. 11.

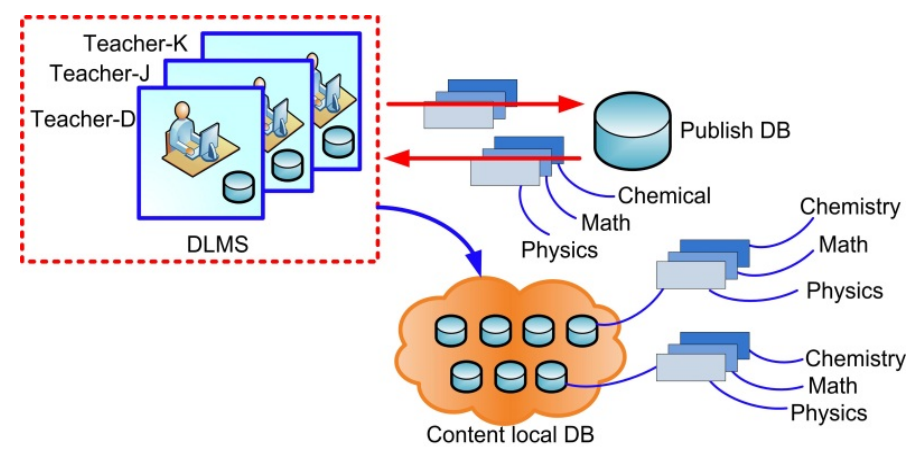

Fig. 11. Scenario-4

\section{Conclusion}

This paper has proposed a transparent digital contents sharing and knowledge sharing among science teachers. It has been also described how the transparent digital contents sharing occurred based on SECI and CMMI model. The prototype system was developed by RESTful Web service as described detail elsewhere. The scenario how IT contributes to four maturity levels was also illustrated. The results showed that science teacher hoped to use the prototype in order to share their digital contents and knowledge transparently.

\section{References}

1. Lester, A., Gerhard, T.: The Future of Distance Learning - The Process and the Product. In: Proc. of Annual International Conference, ITHET IEEE, F1A-K - F2A-2 (2005)

2. Ellis, K.: Field Guide to Learning Management Systems, http://www.astd.org/ /media/Files/Publications

3. Sakoda, M., Wada, Y., Tsuji, H., Seta, K.: Social Network Service with Maturity Level for Science Teachers, pp. 1718-1723. SMC/IEEE, San Antonio (2009)

4. Wada, Y., Sakoda, M., Tsuji, H., Aoki, Y., Seta, K.: Designing Sticky KnowledgeNetwork SNS for Japanese Science Teachers. In: Smith, M.J., Salvendy, G. (eds.) HCII 2009, Part I. LNCS, vol. 5617, pp. 447-456. Springer, Heidelberg (2009)

5. Nonaka, I., Takeuchi, H.: The Knowledge-Creating Company: How Japanese Companies Create the Dynamics of Innovation. Oxford University Press (1995)

6. Carnegie Mellon University, Software Engineering Institute: The Capability Maturity Model: Guidelines for Improving the Software Process. Addison-Wesley (1995) 
7. Chrissis, M., Konrad, M., Shrum, S.: CMMI: Guidelines for Process Integration and Product Improvement. Addison-Wesley (2003)

8. Fielding, R., Taylor, R.: Principled design of the modern Web architecture. ACM Trans, TOIT 2(2), 115-150 (2002)

9. Fielding, R.: Architectural styles and the design of network-based software architectures. PhD Thesis, pp. 76-106. University of California, Irvine (2000)

10. Japan Science and Technology Agency: Rikanetwork (2013), http: //www.rikanet.jst.go.jp/ 